\title{
Julia Prendergast
}

\section{Narrative and the unthought known: The immaterial intelligence of form}

\begin{abstract}
Reflecting upon the evolution of my fractured novel The Earth Does Not Get Fat (2018), this article asks how narrative form represents underlying ideas. This inquiry reflects an abiding interest in the concept of ideasthesia, or 'sensing concepts' (Nikolić 2016). Ideasthesia is a means for deconstructing the ways in which writers sense concepts or ideas in metaphorical or associative ways. As I investigate the development of the fractured form and polyphonic voice in my novel, I take an interest in form as a metaphorical map, a 'linguistic bridge' (Cacciari 2008) between the brain and the mind. With reference to Christopher Bollas' concept of the unthought known (Bollas 2014; 2017), I probe the relationship between narrative structure and latent themes. This extends contemporary debates about form and theme, investigating how fiction writers use cross-sensory modalities and experiential knowledge to plot concepts or ideas. Further, this analysis invites discussion about how ideasthetic practices in narrative represent creative problem-solving. This article focuses on the realist text as a sensory narrative image, a form of abstracted realism.
\end{abstract}

Keywords: creative writing, ideasthesia, unthought known, embodied cognition, abstracted realism

\section{Introduction}

What is the relationship between the ideas that underlie narrative and the form used to convey those ideas? What are the dynamics of the conversion process? What modes of poiesis are involved?

Poesis is simply defined as '[c]reative production, especially of a work of art';

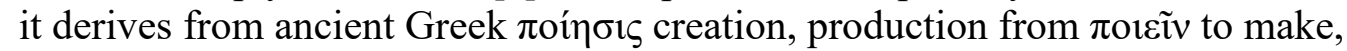
create, produce $+-\sigma i \varsigma^{\prime}$ (Oxford Living Dictionary 2018). This article is a retrospective reflection upon the evolution of the making-creating-producing of my fractured novel The Earth Does Not Get Fat (2018). As I consider the relationship between the fractured narrative form and underlying themes/ideas I am drawn to Danko Nikolić's neuroscientific concept of ideasthesia as a method for articulating how writers 'sense' concepts (ideas) in metaphorical and associative ways. Ideasthesia arises from the 'Ancient Greek words idea (for concept) and aesthesis (for sensation). Hence [...] the term ideasthesia [or] sensing concepts' (Nikolić 2016).

In this article, I will argue that ideasthesia can be a useful means for understanding meta-level processes in creative writing practice. The form of my novel The Earth Does Not Get Fat was not consciously determined or 
logical. Many of the chapters in the novel were first published as standalone short stories. The characters would not 'rest' and the result is a novel in multiple first-person voices and shifting temporal frames. I wrote from the middle, to the beginning, to the end - from the mother's original trauma, to the daughter's experience of the traumatised mother, to the mother's past, and finally to the narrative's temporal present. For publication, I arranged the chapters in a different way: first the daughter's voice in a narrative time that closely precedes the narrative's temporal present, followed by the trauma (in the mother's voice), and finally to the narrative's temporal present.

What was happening in this seemingly haphazard process of writing? What is the relationship between underlying narrative themes and the form of the novel? What does the chaotic methodology reveal about the work my mind was doing when I was not cognisant of the work my mind was doing? As I progressed, I was distracted by my reservations about the evolving structure. I wondered if I could create a cohesive whole from the kaleidoscopic fragments. My inclination was to 'rein it in': draw it together as a cohesive whole. I thought perhaps I should rewrite the material in one voice, or chronologically, or introduce a third person narrator to pull things together. I understood that publishing literary fiction was a sliding scale of virtual impossibility, and I had a sense of how experimental literary forms tipped the scale. The problem was that despite the challenges of polyphony and the scattered chronology, the story existed only as a fractured text - I could not write it another way. My progress necessarily involved unpacking the significance of the fractured form the narrative was taking.

In an article I published in 2018, I unpacked central tenets of Nikolić's 'ideasthesia balance theory' in relation to practice-based examples from one of my short stories (Prendergast 2018a). In that article, I suggested that writers slip into other ways of seeing in order to explicate imagined experience as sensory data. I tracked ideasthetic manoeuvres in the form of concrete and specific sentence-level details in the story 'Like Clay', and on that basis suggested that writers employ ideasthetic processes in order to create fictional characters and a fictional narrative world, transposing sensory experience in a movement towards experiential representation, and capturing an idea through the muted repetition of concrete and specific detail.

In this article, I intend to extend that earlier discussion, examining ideasthesia balance theory as it applies to the relationship between methodology, form and content in the context of longer form fiction. I remain attentive to the question Nikolić posed of my writing process in personal correspondence:

[Ideasthesia balance] theory proposes the "rule" that the strongest aesthesia must be coupled with the strongest idea. Do you see that in your story? At which point? These are the things I am tremendously curious about (Nikolić 2017: personal email correspondence)

Ideasthesia balance theory is based on 'the relationship between meaning and experience as the two forces of ideasthesia' (Nikolic 2016: 4). With this in mind I interrogate the structure of The Earth Does Not Get Fat, foregrounding Nikolić's 'rule'. From my authorial perspective, the mother's lived experience of trauma is central to the narrative. Her trauma is narrated as a composite picture, a play-off between perspectives - Chelsea's sensory perception of her mother's suffering and Annie's lived experience of trauma, the temporal shifts and gaps in memory, and the layering of each character's experiential understanding of trauma and grief. The narrative structure has a 'this plus this' 
style - parts to whole, fragmentary and kaleidoscopic. I consider the individual narrative 'episodes' - the voices as they relate to form and meaning, overall.

In this way, I extend my previous analysis of concrete and specific narrative detail in order to examine a comparatively macro issue: ideasthetic practices as they relate to narrative form. This deepens an existing meta-analysis of sensory and experiential knowledge in creative writing. As Nikolić reminds us, the world of the primary repressed unconscious where sensory and experiential knowledge resides is 'for the most part [...] unconscious and hence not easy to describe in words' (Nikolić 2016: 4). It is based upon:

Phenomenal experience, also known as qualia. Sensations are about the way things [feel] and "are like". It is about the redness of a red colour, and the sourness of a lime. Sensations make up our inner mental life and "light it up" so that life does not happen "in the dark". (Nikolić 2016: 5)

I consider the haphazard evolution of the text as an act of creative problemsolving: a reconstruction of my experience of what grief and traumatic memory are like.

In this article, I am also further developing the concept of experiential representation, as outlined in an article I published in Current Narratives (Prendergast 2011: 25-34). In that article, I compared the act of narrative representation with the processes of remembering, particularly traumatic memory processes, suggesting that each act is a gesture towards original embodied experience. Through its distinct focus upon the relationship between meaning and experience, and particularly the sensory nature of experiential knowledge, the concept of ideasthesia provides a means for extending previous analyses about narrative as a form of experiential representation.

Nikolić attends to the complex relationship between meaning and experience when he suggests that meaning: 'is much wider than what can be verbalized $[\ldots]$ the number of concepts that we have is much larger than those that can be named or expressed in words' (Nikolić 2016: 4). Despite my initial and significant reservations about the fractured form, I came to understand the structure as a metaphorical application of my sensory and experiential understanding of central themes - trauma, grief and memory - as fractured and polyphonic. In this way I agree with Flannery O'Connor, who suggests that 'the form is organic [...] it is something that grows out of the material' (O’Connor 2006: 528).

\section{Writing The Earth Does Not Get Fat}

What is the novel about? The following extract from the novel provides some insight into the character of the broken mother, Annie:

She looked like someone who has had a hard life and no money to take care of herself, like a broken woman at the end of the world, dead on her feet, skin slapped over her bones like white paint, old white paint, slightly yellow. Her shoulders and collarbones were sticking out of her skin like ... like nothing. There is nothing I know that is as awful as her bones poking out of her dirty yellow chicken-skin. (Prendergast 2018b: 35)

The publisher's summary on the novel's back cover blurb focuses on the character of the caregiver/daughter, Chelsea: 
Chelsea doesn't attend school much any more. She is carer for her mother who is sinking further into depression after a trauma, and her Grandad who has slipped into full-blown dementia. Her father is long gone; others are shadowy memories - intangible like dreams. Barely known ghosts make for strange company. Then a parcel arrives and in it are questions - about her mother and her past self, their shared histories, and the people and place from which they've run. (Prendergast 2018b: back cover)

In the latter chapters of the book, Annie speaks in her own voice: she speaks about the past in present tense, as if she is still there. In this way, the novel inquires into the ramifications of trauma and the nature of grief. As I progressed with the writing, I came to an appreciation of the emerging shape of the work as indicative of the work my mind was doing when I was not cognisant of the work my mind was doing. In other words, I became aware of my writing mind engaging my experiential understanding of grief and trauma through fictional characters and a fictionalised narrative world:depicting one family's experience of grief and trauma within a very particular context. As Nikolić suggests, sensation is rooted in associations and experience; in this way, sensory knowledge is idiosyncratic. Further, as Edith Wharton suggests, the world of narrative is focused through a very specific lens:

The impression produced by a landscape, a street or a house should always, to the [writer], be an event in the history of a soul [...] it must depict only what the intelligence concerned would have noticed, and always in terms within the register of an intelligence. (Wharton qtd in Hodgins 2011: 79)

As I pay attention to the relationship between central narrative themes and the representation of these themes in form and content, I am attentive to detail as it relates to a unique form of consciousness, and in this case to multiple central characters. I come to understand how making-creating-producing a representation of trauma and grief might involve layered stories and stratified voices. This reminds me of O'Connor's remarks about the labour of narrative the way narrative is necessarily focused upon capturing one thing in terms of another, capturing an idea through concrete and specific narrative detail:

The fiction writer has to realize that [they] can't create compassion with compassion, or emotion with emotion, or thought with thought. [They have] to provide all these things with a body; [they have] to create a world with weight and intention. (O'Connor 2006: 524)

While Nikolić takes an interest in 'what is happening in the minds of people while they experience art', arguing for 'a particular relationship between the depth of meaning and the intensity of sensation' (Nikolic 2016: 4, 5), I am interested in the concept of ideasthesia as it applies to producing art. In this way, I approach Nikolić's theory from a practice-based perspective, from the point of view of a fiction writer interrogating the relationship between the fractured form and central themes. This is an original contribution to contemporary debates about form and theme in narrative, asking how creative writers use cross-sensory modalities and experiential knowledge to plot concepts (ideas). Further, this analysis invites discussion about how ideasthetic practices in narrative represent creative problem-solving.

In unpacking my experience of writing practice as a journey towards understanding, I am drawn to Franz Kafka who captures the writer's experience 
of being distracted by the evolving trajectory of the narrative:

My feeling when I write something that is wrong might be depicted as follows[...] A [person] stands before two holes in the ground $[\ldots]$ waiting for something that can only rise up out of the hole to the right. Instead, apparitions rise, one after the other, from the left; they try to attract [the writer's] attention and finally even succeed in covering up the right hand hole. (Kafka qtd in Corngold 1996: 84)

It was only through ongoing interrogation of the novel's fractured structure that I came to understand form as a metaphorical representation of the novel's central themes. In this way, I realised I was utilising sensory and experiential knowledge that was known experientially, but not necessarily consciously thought-plotting that knowing as raw concrete detail, as other, through the medium of story.

\section{Drawing on Christopher Bollas' concept of the unthought known}

In order to explicate my understanding of the emerging structure of the novel as a narrative pattern - something I understood experientially but not necessarily consciously - I was drawn to Christopher Bollas' work The Shadow of the Object: Psychoanalysis of the Unthought Known (2017). Here, Bollas 'integrates aspects of Freud's theory of unconscious thinking with elements from the British Object Relations School' (Bollas 2017: preface). He argues that 'within the analytic relationship it becomes possible, at least in part, to think the unthought' (2017: preface). Most pertinently, in the context of a retrospective analysis of my methodology in writing The Earth Does Not Get Fat, Bollas argues that 'aspects of the unthought known - the primary repressed unconscious - will emerge during a psychoanalysis, as a mood, the aesthetic of a dream, or in our relation to the self as other' (2017: preface). In retrospect, I recognise these aspects as having influenced the narrative structure and polyphonic voices of the novel, particularly my representation of grief and traumatic memory. This representation is othered as it is imagined through multiple first-person perspectives in a fictional narrative world. In this way, I draw a connection between Bollas' discussion of the 'unthought known' that emerges through the relation to the self as other (in psychoanalysis) and ideasthetic practices in narrative: utilising experiential (primary repressed, unthought known) knowledge in an othered relation to the self.

Bollas introduces a 'discourse of object relating' within the context of 'tracing the private logic of sequential association' when listening to a 'patient's free associations (or broken speech)' (2017: introduction). I propose that, in some respects, my relationship with the evolving text mimics the psychoanalytic relationship. In the article 'Creativity and Psychoanalysis' Bollas suggests: 'In the struggle to engage the invisible, the analyst (like the artist) breaks the figure; not to find out what is inside but to realise the immaterial intelligence of form' (Bollas 2014: 19; brackets in original). I am taken with this concept of immaterial intelligence as a means of explicating ideasthetic practices in the act of narrative making. In order to articulate my understanding of the relationship between meaning and experience, as it applies to a retrospective analysis of my methodology in writing the novel, I examine the relationship between the fractured narrative structure and underlying themes, arguing that the fractured structure is a (material and yet metaphorical, hence also immaterial) representation of underlying (unthought known, immaterial) ideas. 
Like Nikolić, Bollas takes an avid interest in the arts, bringing richly textured ideas from psychoanalysis to contemplate content, form and methodology in arts practice (music, visual arts, writing). Focusing Sigmund Freud's method of free association together with the concept of the unthought known, Bollas proposes that:

Even as the patterns [in works of art] typify and identify the works as the product of one artist, they open the project as a question [...] What is this? What is one looking at? From which perspective? (2014: 6)

Broadly speaking, these are the questions I faced as the manuscript evolved, constantly renegotiating what the manuscript was within the context of the perspective/s from which I was assessing it. In this way, I tried to assess creative practice logically, in order to try to understand the unprompted emergence of the fractured form. I was trying to logically assess my engagement with alogical processes of association: to understand the impact of ideasthetic engagement with narrative themes and the influence of the unthought known.

\section{A methodology leading to undreamt of territories}

Despite my initial resistance to the fragmented form I persevered, but I did so in a state of distraction. This state of affairs is true to the meta-level experience of many writers, and yet it is a very challenging process to describe incrementally and logically. In this way a logical analysis of my methodology led me to undreamt of territories. Bollas identifies the limitations and possibilities of conveyance when he speaks of artists being 'irked' by critical examination:

not only because they might be distressed with the judgement, but also, it seems to me, because they have entered a different realm, which is not the written word, even if their medium is prose fiction. (2014: 14)

On a related note, Bollas describes the reassurance he feels when experiencing the work of an artist he admires:

These are works I feel I know but what do I know [...] these works evoke the experiencing me that exists in and through the medium of paint. It brings something out in me, or, to put it in the vernacular, it "speaks to me". (2014: 13, 14; my emphasis)

These references point to the sense in which making-creating-producing and engaging with creative works relies upon sensory and experiential knowledge that is not necessarily available to logical consciousness. My experience of "writing towards knowing" is not unique. I am reminded, again and again, of Kafka's earlier description of unmotivated apparitions, of writing in a state of distraction (qtd in Corngold 1996: 84). I empathise with authors who arrive at an understanding of the narrative trajectory only cumulatively and retrospectively.

It is accurate to suggest that, methodologically, my process is impulsive and immersive, allowing the subject matter to shape the form. Perhaps in part this explains the sense in which writing may be a metaphorical act of minimal selfconsciousness - an acutely empathic act in which we sense concepts through an imagined lens. In this realm, narrative detail is capable of radical 
transformation - as the writer thinks the unthought, the 'unthought known' becomes incrementally recognisable - and the dissimilar is often rendered similar. This is consonant with Freud's thesis in 'The Uncanny' - the mystifying process Freud outlines where 'the word heimlich [...] develops in the direction of ambivalence until it finally coincides with its opposite, unheimlich' (Freud 1919: 421). Such analysis recognises the spirit of Aristotle's concept of metaphor as an appreciation of the 'similarity [to homoion theorein] in dissimilars' (Ricoeur 1977: 23).

In this way, the writer may be retrospectively aware of that which is known and yet unthought (in conscious, logical terms), at a primal moment of narrative composition. Bollas quotes the following example from Wallace Stevens' reflections on the process of writing poetry:

While there is nothing automatic about [a] poem, nevertheless it has an automatic aspect in the sense that it is what I wanted it to be without knowing before it was written what I wanted it to be, even though I knew before it was written what I wanted to do. (Stevens qtd in Bollas 2014: 12)

Stevens' description of the (non-automatic) automatic aspect of the poem, brings Bollas' unthought known into sharp focus. Reflecting more broadly upon the journey from idea to artistic artefact/object, Bollas suggests that: ' $[\mathrm{t}]$ his transition is not representational. It is presentational. [It] has not existed before' (Bollas 2014: 12). The narrative artefact, as object, has not existed before and yet it relies upon that which is known at the level of the primary repressed unconscious: it relies upon cross-modal sensory and experiential knowledge, as prior knowledge, informing the representation of an idea at the surface level of the text. Ideasthetic processes allow for the transformation of ideas: for ideas to be presented as other. The process of transition is made possible through sensory and experiential engagement with central themes: this relies upon the associative networks that inform the relationship between the surface content and the latent content in narrative.

I unpack the intricacies of these networks at some length in earlier articles, including 'Boats on the Roof of the House: The Shadowy Flux of Alterity' (Prendergast 2013) and 'Light the Towel: Narrative and the Negotiated Unconscious' (Prendergast 2012). These articles explore the idea that, at the primal moment of narrative composition, seeing and logical knowing separate. During such a phase seeing and knowing are alogical: they involve a process of seeing beyond, outside the constraints of logic. This is what David WhishWilson means when he speaks of "the "splitting" of normal consciousness whilst in the creative state' (Whish-Wilson 2009: 85). When the mind is split, voice is pluralised. I propose that this aspect is attributable to the work of the imagination in creative texts, and apparent in the relationship between latent and manifest content in narrative. These insights rest upon Freud's presupposition about the symbolic quality of the sign in the dream and, by extension, memory. A house with a boat on its roof, as an example of a symbol in Freudian dream analysis (Freud 1900: 400), means something more when we see beyond the level of the concrete and specific detail of the dream: when we unpack the sign as symbol.

It is through an analysis of the relationship between structure and theme, within the context of the broader discussion focusing on manifest and latent content in the novel, that I come to understand Bollas' concept of the presentational object. The presentational object, as it applies to the literary artefact, is generated by embodied and experiential knowledge as it resides in the unthought known - a type of embodied cognition. It is my contention here that 
Bollas' ideas can provide the creative writer with significant insights into ideasthetic processes as applied to the writing of fiction.

\section{Metaphor and imagination as deeply contextual}

To engage with ideas in ideasthetic terms is to employ experiential (unthought known) knowledge to fictional characters and a fictional narrative world: it is to engage with ideas in sensory terms and plot them as concrete and specific narrative detail. Cognitive linguist George Lakoff identifies the limitations of the 'mind as machine paradigm', suggesting that the 'disembodied' mind may be able to 'describe' but cannot

explain $[\ldots]$ experiential structures that inform the basis of metaphorical concepts [and further] only an understanding of the dependence of mind upon the body for the content of its concepts can explain such characteristics of human conceptual systems. (Lakoff 1987: 351)

The dependence of the mind upon the body for experiential content is at the heart of an analysis of ideasthesia and creative writing practice. Psycholinguist Cristina Cacciari's analysis of sensory-based metaphors deepens this discussion, encouraging speculation about motivation and embodied cognition within the broader context of creative writing methodology. Cacciari suggests that:

Metaphorical language expressing sensory experiences does not reflect an abstract-amodal combination of word senses, but rather the neural endowment necessary for treating sensory information[...] Neurosciences offer an extraordinary opportunity to investigate metaphors for what they might concretely be, linguistic bridges between the mind and the brain. (Cacciari 2008: 439)

As I interrogate the fractured structure of The Earth Does Not Get Fat, I see central themes reflected in the structure: in simplistic terms, brokenness as fracturing. This captures my experience of the interaction between the unthought known and full logical consciousness, in methodological terms. This is a deeply contextual activity, unpacking creative practice as a combination of conscious and unconscious process, assessing the ongoing interchange between one and the other. In the article 'The brain is a context machine', Nikolić suggests that:

Consciousness may be much less of a theoretical problem if the brain theories, e.g. those of vision [...] immerse considerably deeper into contextual considerations of the perceptual principles than is the case today. (Nikolić 2010: 36)

As I examine the way imagination informs ideasthetic practices in creative writing, I ask about the relationship between intentionality and practice, taking a specific interest in unpacking methodological acts that are not fully consciously determined, and considering the way in which my methodology is informed by experiential knowledge. To allow the subject matter to shape the form is to immerse oneself in the experiential world of self as other, shaping the imagined-known through the experiential-known. The concept of ideasthesia provides a means for articulating the relationship between ideas and the expression of those ideas: inviting conjecture about the multi-sensory modalities that underpin perceptual experience, investigating the way writers 
draw from this rich resource - while bearing in mind that perceptual experience is only partially understood at the level of full, logical consciousness. The act of imagining, of sensing ideas in narrative methodology, is an ideasthetic, empathic engagement with ideas - drawing upon experiential, cross-sensory data and applying it metaphorically in order to transform ideas through words.

In the article 'Crossing the Senses in Metaphorical Language' (2008), Cacciari notes that:

Experientially, the boundary between sensory modalities can easily be broken when we infer, for instance, the haptic quality of a surface (e.g., its roughness) from seeing it. (Cacciari 2008: 430)

The concept of hapticity illustrates cross-modal sensory engagement as it relates to understanding and, pertinently, as it relates to the realist text as a sensory narrative image. As we engage ideasthetically with the ideas that underpin narrative, we engage imaginatively with the haptic quality of the idea - we cross sensory modalities in order to show what trauma, grief and memory are like. This is apparent at the concrete and specific level of the individual sentence but also at the level of form and structure in the overarching text. As I came to understand the structure of my novel as a metaphorical representation of brokenness, of memory within the context of grief and trauma, I came to accept the fragmented form and the polyphonic voices. In this way, as I argue in my article 'Grinding the Moor - Ideasthesia and Narrative', ideasthetic manoeuvres in narrative are an act of homage to an otherwise irresolvable idea (Prendergast 2018a: 428).

A focus on ideasthesia allows me to articulate my experience of creative writing process as a metaphorical gesturing toward an unthought known realm that is beyond words or, at least in Nikolić's (2016: 4) terms, 'unconscious and hence not easy to describe in words'. Ideasthetic flips and turns of mind in narrative play assist in developing the architecture of the story and, therefore, in making the text intelligible to logical consciousness. In this way sensory engagement with idea informs the structure of the text.

In the article 'Haptics, the Secret Senses; the covert nature of the haptic senses in creative tacit skills', Prytherch and Jerrard interview a group of highly skilled tactile artists about the part played by the senses in skilled manual processes. They argue that:

much of sensory information being produced moment to moment is filtered by gating mechanisms [...] and, as a rule, is managed at a preconscious level[...] In this respect haptics should be viewed as a secret sense and its importance to the practicing artist should not be underestimated. (Prytherch \& Jerrard 2003: 384)

As I take an interest in how ideasthetic practices in narrative affect both the content and form of the finished artefact, I recognise that the work of association hinges upon the management of sensory data at the pre-conscious level. In this way, I understand Cacciari's suggestion that it is 'not a linguistic statement but a perceptual experience to cross sensory boundaries' (Cacciari 2008: 426, 427). In explicating the cross-sensory nature of experiential knowledge as it underpins language, Cacciari gives voice to the connection between meaning and experience that is crucial to Nikolić's theory of ideasthesia. Nikolić discusses ideasthesia as an occurrence 'in which activation of concepts produces phenomenal experience' (Nikolić 2016: 1). Examining 
ideasthesia from a practice-based perspective, I emphasise the ways experiential knowledge and (unthought known) phenomenal experience informed the structure and tone of my novel, recognising that my analysis is retrospective and exists in relation to self as other: recognising personal experiential knowledge as it is reflected through the lens of imagined others in fictional texts.

\section{The Earth Does Not Get Fat as transubstantial object}

In consolidating this discussion, I return more directly to the process of writing the novel. In this final section of the article, I contemplate the ideasthetic processes at play in the development of The Earth Does Not Get Fat as an investment in the sensory and experiential, and I consider its status as an object that, in Bollas' terms, has its own processional integrity.

As I toil with the evolving narrative, I hope to make sense of what I've done. I wonder why I don't 'get it' until I've 'done it'. I think it's never going to take shape until it takes shape. In this way, I unpack from 'end to beginning'. This can be an inordinately frustrating, unavoidable way to work and yet I am grateful for the compulsion: for the irresistible urge of the (unresolved) idea.

Helen Garner has described the labour of writing in the following way:

Every day I work on the edit of my book. I slog away, shifting chunks of material and then moving them back, eating my salad in a daze, wondering if the linking passages I've written are leading me up a garden path, or are sentimental, or violate some unarticulated moral code I've signed up for and feel trapped in or obliged to. The sheer bloody labour of writing. No one but another writer understands it - the heaving about of great boulders into a stable arrangement so that you can bound up them and plant your little flag at the top. (Garner 2016: 107)

Janet Frame has also described the journey towards a satisfying narrative structure as an emergent process:

The whole of writing is expressing an emerging pattern or shape. And the satisfaction is when the shape is concluded [...] this for me is the real joy of writing $[\ldots]$ [A]s one is writing a pattern grows and everything seems to fall into place - very exciting, very exciting just to see it. (Frame qtd in Hodgins 2001: 162)

In my ongoing attempts to understand the relationship between idea, form and method, Nikolić's insights into the overarching concept of ideasthesia continue to provide a pathway for explicating writing as an act of blind motivation - an act resulting in the presentation of an object (idea) that is primarily understood in sensory and experiential terms, but not necessarily available to full logical consciousness.

In this, I am drawn to Bollas' identification of art as a transubstantial object:

The term "transubstantial object" allows me to think of the instrinsic integrity of the form into which one moves one's sensibility in order to create: into musical thinking, prose thinking, painting thinking[...] The "object" through which we create - painting, prose, music - has its own processional 
integrity, its own laws, and when we enter into it to express our idea within its terms, we shall be altered by the object. (Bollas 2014: 11, 14)

Once again, we are in the realm of the metaphorical relations between sensory and experiential knowledge. Wrangling with narrative complexity, working backwards to unpack the work my mind was doing when I was not cognisant of the work my mind was doing, provides insights regarding the elusive principles at play in the act of narrative making.

In The Aesthetics of Emotion: Up the Down Staircase of the Mind-Body (2016), psychologist Gerard Cupchick searches 'for meaningful relations between "what artists do and what they think"" (Cupchick 2016: 216). Cupchick cites developmental psychologist Heinz Werner, who 'believes that emotions develop out of an undifferentiated affective state of excitement in which sensory activities are combined (as in synaesthesia)' (Werner qtd in Cupchick 2016: 137). Following Werner, Cupchick notes that:

Such primitive and concrete action is characterized by "immediacy, limited motivation, and lack of planning"[...]

This kind of experiential and perceptual process is tied to syncretism, which is "characteristic of primitive emotion" and "somatic-motor" activity. (Cupchick 2016: 136)

This is consistent with Bollas' presentational object, in the sense that it relies on the forces of emotion and re-action in order to present an object of art. Further, in coming into being the object takes a form through which we express our ideas, a form which in turn acts upon us as the author or creator. In this way the object is also consistent with Bollas' concept of the transubstantial object (Bollas 2014: 11). The object of art makes us aware that there are underlying perceptual principles at play. So while it is presentational, in that it has not yet existed, it is also transubstantialin that it takes on a tangible form that represents experiential understanding. The process of translation, from experiential knowledge to the (transubstantial) object, illustrates Cacciari's proposal that 'sensory-based metaphors [...] reflect the structure of the perceptual experience [...] and of the neural circuits subserving them' (Cacciari 2008: 439).

Bollas targets the relationship between our response to emotion, on the one hand, and the artefact as an object that represents ideas, on the other. In this way, Bollas lauds emotion as the inner event: '(e)motion (from "movere") or moving experience, is an inner event and might get us closer to what we try to signify by affect or feeling' (Bollas 2014: 6). Following Bollas, I suggest that ideasthetic engagement with ideas in the act of narrative making gives form to inner events. On the subject of conveyance and the inner event, Irish-born British artist Francis Bacon, renowned for figurative and experimental works, asks: 'how can I draw one more veil away from life and present what is called the living sensation more nearly on the nervous system and more violently?' (Bacon qtd in Walsh 2009: 236). In answer to Bacon's question, I suggest that I am able to convey living sensation more violently through ideasthetic engagement with narrative ideas, utilising all that is- $I$ to engage experientially with the self as other. Empathic imagination is at the heart of this process.

Kylie Fitzpatrick, writer and theorist in the field of empathy and writing, takes a particular interest in neuroscientific findings focused on reading and empathic engagement: 'Neuroscience has identified a physical site in the brain that is stimulated, creating an empathic response when we say or write "I"" (Fitzpatrick 2017: 22). Fitzpatrick draws attention to the mind's inability to 
discriminate between the imagined I (the reader's association with the firstperson character) and the 'real' $I$ (the reader as distinguished from the fictional character). Fitzpatrick focuses on the work of scientist Joe Dispenza, who takes a particular interest in neuroscience as it relates to our ability to imagine an alternate reality: 'The brain, in its chemical response to data, does not discriminate between that which is real and that which is suggested to it via memory and imagination' (Dispenza qtd in Fitzpatrick 2017: 22).

While I approach the issue of empathy from a practice-based perspective focusing on ideasthesia as an empathic engagement with idea in narrative practice, rather than focusing on the reader's response - we are nevertheless "speaking the same language". If I inhabit the self as other through ideasthetic gesturing in the act of narrative making, I am suggesting that my mind experiences the subjective world of the other-I as a highly-tuned reader experiences the world of the I narrator. While the conscious, logical mind distinguishes between $I$ and other, the brain does not necessarily follow suit. The brain is not working logically. The brain, unlike logical consciousness, does not automatically distinguish between deep, sensory imagination and experience.

\section{Conclusion}

I began this article by inquiring into the nature of the relationship between the ideas that underlie narrative and the form used to convey those ideas. What are the dynamics of the conversion process, I asked, and what modes of poiesis are involved?Drawing crucially and significantly upon Bollas' concept of the unthought known, from psychoanalysis, as it relates to Nikolić's concept of ideasthesia, from neuroscience - within the very specific context of a selfreflective analysis of the process of writing a fractured work of long-form fiction - I have been able to track meta-level processes in tangible terms, analysing narrative structure as it relates to theme.

I agree with Wharton: the writer can't create compassion with a signifier. Compassion is formless - in and of itself it is an emotive entity that resides in the realm of experience. To plot otherwise formless experiential data is to say by showing - to think the unthought - to give the unthought known a tangible shape, transubstantiating ideas using concrete and specific narrative architecture. I have explicated this process with reference to theories of metaphor and embodied cognition as they relate to creative practice and imagination - theories at the heart of the work of Lakoff, Cacciari, Cupchick and Fitzpatrick, respectively.

I have suggested that ideasthetic practices, relying upon the experiential, the unthought known, and imagined bodily action, play a direct role in the way writers translate ideas into concrete and specific narrative detail. I have also hypothesised about how ideasthetic practices prime metaphor creation. This is evident not only at the level of the sentence, but also at the level of form, as a metaphorical map of underlying themes. In this way I make sense of the fractured narrative in my novel The Earth Does Not Get Fat as a pattern that is more than the sum of its parts.

My focus on ideasthetic practices as imaginative, empathic engagement that is emblematic of the relationship between ideas and sensory data is in keeping with Bacon, who suggests that 'art lies in the constant struggle to come near the sensory side of objects' (Bacon qtd in Walsh 2009: 248). To trap the object imaginatively is to capture it metaphorically, to find an imagined objective 
correlative. Perhaps most pertinently, Bacon argued that the most pertinent issue was the merging of 'idea and technique' (Bacon qtd in Walsh 2009: 237). Walsh elaborates: 'the prerequisite to realizing the full potential of the painted image was its synthesis with the idea which it was seeking to bring into form' (Walsh 2009 2009: 237).

In unpacking the meta-level processes that merge idea with technique, I have sought to articulate my experiential understanding of the linguistic bridge between the mind and the body - reflecting on ideasthetic manoeuvres in the writing of The Earth Does Not Get Fat as an empathic, sensory engagement with an original idea that in turn becomes other. In this way I contemplate a mind that may not distinguish between I the author and the other-Is born of ideasthetic imagining - both draw upon the same pool of experiential knowledge, including unthought known (primary repressed unconscious) sensory data, in order to translate ideas in concrete and specific terms in narrative.

Unpacking the influence of ideasthetic engagement with ideas as they relate to form in creative writing allows writers to track meta-level processes of association in practice - to see the evolution of the presentational object, which had not yet existed as a tangible structural entity, become precisely that. Unpacking processes of ideasthetic imagining reveals the generative nature of the activity, inviting speculation about how the experiencing mind conflates deep, subjective sensory imagining and experience. Ideasthetic imagining is a tool for both emerging and established writers to build organically from an initial idea to a more extended analysis of narrative themes.

\section{Acknowledgements}

This article is the result of a presentation at the 'Empathy and Creativity Symposium' hosted by the Centre for Creative and Cultural Research (University of Canberra, AU: June 2018). The symposium constituted the first 'Empathy and Creativity Symposium' in Australia, bringing together cross-disciplinary research and expanding an international dialogue, which started in the Empathy and Writing Group at Bath Spa University (UK). Material from this article was also presented at the 'Great Writing Conference' (Imperial College, UK: June 2018) and the 'International Short Story Conference' (University of Lisbon: June 2018).

\section{Works cited}

Bollas, C 2017 The Shadow of the Object: Psychoanalysis of the Unthought Known, Routledge, Abingdon, Oxon return to text

Bollas, C 2014 'Creativity and Psychoanalysis', in G Fromm (ed) A Spirit that Impels: Play, Creativity, and Psychoanalysis, Routledge, London: 3-20 return to text

Cacciari, C 2008 'Crossing the Senses in Metaphorical Language', in RW Gibbs Jr (ed) The Cambridge Handbook of Metaphor and Thought, Cambridge University Press, Cambridge: 425-446 return to text

Corngold, S 1996 'Kafka's The Metamorphosis: Metamorphosis of the Metaphor', in S Corngold (ed) The Metamorphosis: Translation, Backgrounds and Context, Criticism, W W Norton \& Company, New York: 79-106 return to text

Cupchick, G 2016, The Aesthetics of Emotion: Up the Down Staircase of the Mind-Body, Cambridge University Press, Cambridge return to text

Fitzpatrick, K 2017 'The Search for Meaning', Writing in Education 71, 2:

https://www.nawe.co.uk/DB/wie-editions/articles/the-search-for-meaning.html return to text 
Freud, S 1919 'The Uncanny', in J Rivkin \& M Ryan (eds) Literary theory: an anthology, 2nd edn, Blackwell Publishing, Chichester, West Sussex: 418-430 return to text

Freud, S 1900, 'The Interpretation of Dreams' in J Rivkin \& M Ryan (eds) Literary theory: an anthology, 2nd edn, Blackwell Publishing, Chichester, West Sussex: 397-414 return to text

Garner, H 2016 Everywhere I Look, Text Publishing, Melbourne return to text

Hodgins, J 2001 A Passion for Narrative, McClelland \& Stewart, Toronto, Ontario return to text

Lakoff, G 1987 'The Mind-As-Machine Paradigm', in Women, Fire, and Dangerous Things: What Categories Reveal about the Mind, University of Chicago Press, Chicago: 338-352 return to text

Nikolić, D 2016 'Ideasthesia and Art', Prof. Dr. Danko Nikolic: www.danko-nikolic.com/wpcontent/uploads/2016/02/Ideasthesia-and-art.pdf (accessed 20 April 2019) return to text

Nikolić, D 2010 'The Brain is a Context Machine’, Review of Psychology 17, 1: 33-38 return to text

O'Connor, F 2006 'Writing short stories', in L Anderson (ed) Creative Writing: A Workbook with Readings, Routledge, Oxford return to text

Oxford Living Dictionary 2018, 'poeisis', English Oxford Living Dictionary, Oxford University Press: https://en.oxforddictionaries.com/definition/poiesis (accessed 20 April 2019) return to text

Prendergast, J 2018a 'Grinding the Moor - Ideasthesia and Narrative', New Writing: The International Journal for the Practice and Theory of Creative Writing 15, 4: 416-432 return to text

Prendergast, J 2018b The Earth Does Not Get Fat, UWA Publishing, Perth WA return to text

Prendergast, J 2013 'Boats on the roof of the house: the shadowy flux of alterity', in T Clark, T Mokhtari \& S Henriss-Anderssen (eds) Testimony, Witness, Authority: The politics and poetics of experience, Cambridge Scholars Publishing, Cambridge: 40-48 return to text

Prendergast J 2012 'Light the Towel: Narrative and the Negotiated Unconscious', New Writing: International Journal for the Practice and Theory of Creative Writing, 10, 2: 167-181return to text

Prendergast, J 2011 'Discontinuous Narrative: The Trace Dance', Current Narratives 1, 3: 2534 return to text

Prytherch, D \& B Jerrard 2003 'Haptics, the Secret Senses; the covert nature of the haptic senses in creative tacit skills', Proc. Eurohaptics 200: 384-395. Available at:

https://pdfs.semanticscholar.org/39c5/4b5bd4701b60f1562a9b9329af5c34c947f8.pdf (accessed 20 April 2019) return to text

Ricoeur, P 1977 The Rule of Metaphor: Multi-Disciplinary Studies of the Creation of Meaning in Language, R Czerny, K McLaughlin \& J Costello (trans), University of Toronto Press, Toronto return to text

Walsh, V 2009 ““....to give the sensation without the boredom of conveyance”: Francis Bacon and the Aesthetic of Ambiguity', Visual Culture in Britain 10, 3: 235-252 return to text

Whish-Wilson, D 2009 'Trance, Text and the Creative State', Creative-Writing: Teaching, Theory \& Practice 1, 1: 85-99 return to text 
Lightship Anthology 2 (UK), Glimmer Train (US), TEXT (AU), Seán Ó Faoláin Competition (IE), Review of Australian Fiction, Australian Book Review Elizabeth Jolley Prize, Josephine Ulrick Prize (AU). Julia's research has appeared in various publications including: New Writing: The International Journal for the Practice and Theory of Creative Writing (UK), TEXT: Journal of Writing and Writing Courses $(A U)$, Testimony Witness Authority: The Politics and Poetics of Experience (UK). Julia is Deputy Chair of the Australasian Association of Writing Programs (AAWP). She is a Lecturer in Writing and Literature at Swinburne University, Melbourne.

\section{TEXT}

Vol 23 No 1 April 2019

http://www.textjournal.com.au

General Editor: Nigel Krauth. Editors: Julienne van Loon \& Ross

Watkins

text@textjournal.com.au 